\title{
The Cultural Differences influences on Knowledge Sharing Activities in Construction Project Collaboration
}

\author{
Tri Joko Wahyu Adi and Atif Musbah
}

\author{
Department of civil engineering, Institute Technology Sepuluh Nopember Surabaya (ITS), Indonesia
}

E-Mail: Atif_mohamed1@yahoo.com

\begin{abstract}
In the last decades construction activity has been heavily criticized for its productivity and performance in relation to cultural differences. There have been several studies indicated that the cultural diversity influence the knowledge of the organization, and that result in barriers in knowledge sharing in the multicultural organization. The knowledge spreading manners affected by the cultural in organization due to ethnic, cities, sexual category, local culture, which that might lower level of the knowledge spreading in organization. Therefore, a research study is developed in order to assess the influences of cultural differences on the activity of knowledge distribution in organization project and to determine of extend of the cultural differences to obstacle the individual to share their knowledge within the organization or with other members of the organization and how is that leads to decrease the project's performance. For seeking to achieve the aims of the study a survey questionnaire was used to gather data. System dynamic simulation is utilized to interpret the collected data in order to achieve meaningful information. The results proven that cultural difference is one of the major problems that impact the project performance negatively in the construction industry since it is verified that the cultural difference impacts the knowledge flow among the employees in the construction project which that strongly affects the outcome of the projects and that also leads to decrease the productivity of the project. In addition, the respondents also agree that cultural differences cause unsuccessful safety system in the construction projects. Therefore, the cultural differences should be given careful attention to ensure better project performance.
\end{abstract}

Keywords: cultural differences, knowledge sharing and performance in the multicultural construction industry, (safety, quality, and cost in the multicultural construction projects).

\section{INTRODUCTION}

The construction activity is unique among other sectors as the activities of construction often take place in the open-air in the situations which level of the safety is very low and increasing the level of danger. The construction project workers are coping with continuous switch in the type of work, places of the work and combination of the works in the projects. When the cultural differences have the capability to affect the project performances, thus, the performances of the knowledge management can be impacted by the cultural diversities. The cultural diversities are significant problem to every group of the people or corporation. Culture and culture differences are significantly critical for the international enterprises operating which having employees from different cultures [1]. The cultural differences work as obstacle to the knowledge sharing through the construction organization. Knowledge sharing in simple words can be defined as a way of transferring knowledge of one individual to others individuals, group, or other organizations [2]. To success in organizational management on factor must be taken in consideration which is effectiveness of knowledge sharing.[3] knowledge sharing can be passed from one person who has this kind of knowledge to another who has not this can be done by exchanging of knowledge between employees. To increase the accumulation of organizational knowledge the efficiency of knowledge sharing is required doing so, this will result in better performance of its employees in work. [4]. Explicit or tacit individual knowledge held by the employees can increase the value to the product, customers and benefits the organization [5]. One of sources of organizational knowledge is individual knowledge. Employees and organizations can obtain more knowledge by knowledge sharing process among individuals [5]. The lack of interaction among the individuals within an organization will limit the knowledge sharing [5]. Knowledge shared between employees is related to maximize the benefit of knowledge asset of the organization. Knowledge asset of the organization can be greatly reduced when employees are not sharing their individual knowledge [6].

\section{The Benefits of Collaboration between Organizations}

1. Valuable knowledge Sharing.

2. Prevent inventing what already invented,

3. decreasing unneeded effort,

4. Cost of inventions is reduced.

Experts and experience people can help to create knowledge sharing foundation [7]. Knowledge sharing is significant for collaborative and joint venture has been recognized this was proved by previous studies [8, 9]. Knowledge hoarding has negative consequences and knowledge sharing has benefits these have been noted by researchers. Institutions are now able to retain the knowledge created by their talents members and expertise by using effective knowledge sharing [10]. To increase the efficiency and reduce working time knowledge hating is one good method this is can be done by that an institution or a Company learns from past experience and prevents redundant wok [11]. On the other hand, [12] observed that the cultural differences in companies leading to obstacles in knowledge sharing, in a same way, [13] project teams knowledge sharing behaviour will influenced by assessed the cultural difference. Different cultural background of team members is determined by different aspects such as gender, ethnicity, functions, cities or natural culture resulting in complexity of cultural context, taking in consideration this factor knowledge sharing is affected in negative way. [14] It can be noticed that transferring explicit knowledge in decreased due to cultural differences where in tacit knowledge transfer the 
difficulties is less. Fluency is corporate language is essential for sharing knowledge sharing where the lack of it resulting in misunderstanding multinational and multi cultural settings and effecting the process of learning and knowledge sharing dramatically [15]. [16] stated that the knowledge sharing could be developed throughout a successful communication channels and as well the trust. Trust plays a significant role in how workers transfer and share their knowledge with the others

As the cultural differences are being distinguished as one of the major obstacles that influence the knowledge sharing in the multicultural projects and that leads to decrease the project performance in the multicultural construction organization. Therefore, for this seeks this study will be accomplished to evaluate the knowledge sharing under the influences of the cultural differences in multicultural organization, to what extend the culture difference obstacle the knowledge sharing among individuals from who has it to who needs it in the multicultural organization and how that effects the project performance in the multicultural organization

\section{LITERATURE REVIEW}

The culture can be define as a patterned way of feeling, thinking, acquired, reacting and pass on from one place or person to another. Shaping the special achievements of human groups, and that contains their embodiments in artifacts [13]. This definition consider to be closer [17] in simple words the culture can be defined as the way of the peoples think, what being done, the creation of material products. [13] Acknowledged that the culture also can be defined such as collected experiences of the brains which distinguish one person from another or group from another group. Culture functions such as patterns and forms behavior and self perception in the society and the pass it from generation to the next generation, The cultural differences in international companies operating which having employees from different cultures have become more critical [18]. As long the cultural can influence the performance of the project then the knowledge management is possible to be influenced by dissimilarity of the culture. Cultural diversity is significant problème for all the industries sites and here some factors which it may obstacle the project success in the multicultural organization. Communication barriers were highlighted one of the main obstacles in the transferring the knowledge where a smooth communication play important role in quality improvement process by maintains the spirit and thrust among the individual, the communication is significant guide the works to corporation prospective [19]. Safety culture can be defined as behavior affected by culture. Respect of safety and the attitude of workforce are related to respect and health culture of the company itself. All the risk such as accidents and incidents in the company is shared by them [20]. knowledge management is defined as a technical programs which is utilized for keeping and hand over the shared knowledge [21,22,23] which it is a Collection of knowing what way or manner by establishing techniques and method assisting and make easy the recognition, collected, distribution and use the information or the knowledge to meet their goals by [24]. The knowledge is created by the individuals who has great expertise in the organization and shared in the database or the systems that are built up to assist the individuals or teams those who are with less expertise in the organization. Most of the knowledge at first is tacit in nature, it is laboriously improved during a long period of time via trial and error, and it is less used due to the organization does not know what it knows [25], whilst the explicit knowledge exists there in the words, sentences, documents, sorted data, computer programs and in other different explicit forms. The knowledge sharing is an opportunity to gain an inclusive advantage of the organization capability to come out with solution to the facing problems in the organization and lead to successful business with viable benefits [26]. [27, 28, 29, 30, 31, 32] clarified that the knowledge sharing has positive impact for the team performance, drop in production costs, increase the innovation, improve the ability of the company, increase the business performance, as well as rising the sale level and faster completion of new product and development projects. The fact is no individual knows everything, and no individual has the ability to keep up with relevant new knowledge continually being made entirety. Exchange or share the knowledge among the workers conserves resources and unlimited time for the workers to share out the knowledge that they hold. In mean while the knowledge sharing process has the capability to build a great benefit to the company [33] indicated, by exchanging knowledge, obtaining information the best utilization, collected experiences and gathering the obtained information with the individuals in the organization expert workers can be achieved. By way of sharing knowledge and the information the individual workers get to gain more knowledge from the experiences of their work and from the other individual's experiences of the organization. Furthermore, [33] pointed out it is not only successful learning strategy in terms of the cost but also validate individual workers collected of knowledge. Several studies have attempted to set up the causes which influence the transfer of the knowledge in the multicultural construction project, from the mentioned in the literature review it observed that the knowledge sharing is influenced by the communication, trust, learning and innovation in multicultural organizations as shown in figure (1). The weakness of the used language can be most obstruct for exchanging the knowledge and its main of the communication difficulties and misunderstandings in the cultural difference origination which that influence the process of the learning. From the previous researches

determined that if the organization has trusted culture the sharing knowledge would be easier which that leads to improve the innovation and learning. Whilst the trust between the employees and the organization can be improved by opening communication channels, also it observed that the learning and contributing takes the field to the most important steps for the innovation and entire organizational implementation

\section{RESEARCH METHODOLOGY}

In research methodology, the cultural differences influence the flowing of knowledge in the multicultural organization and its effect on project performance will be acknowledged. In order to do that it is needed to specify the factors that obstacle the knowledge sharing between the individuals in the multicultural construction projects and how 
it influence the project performance.

From the Literature review, the factors which are impacted by the cultural differences and hinder the flowing the knowledge among the team workers in multicultural project were recognized. The researchers agreed that the native languages differences in the multicultural projects hold back the knowledge sharing among the workers. The trust in the multicultural project consider one of the factors which encumber the individual to separate their work experiences with other members in organization which that lower the capacity of learning of the workers as well as decreasing the level of the innovation in the organization and in over all leads to decreasing the project productivity.

To evaluate the degree of the impact or the influence of the cultural differences on the knowledge distribution in the multicultural projects and to what level that influence the project performance a bunch of questions were established and distributed to the individual workers of a multicultural construction project. The questionnaire is divided to two types of questions. The first part of the questions focuses about the usefulness of the knowledge sharing in the construction projects and its impact to the project performance. While the second part of the question concentrates about the cultural differences impact on the knowledge sharing and how is reflect on the performance of the project.

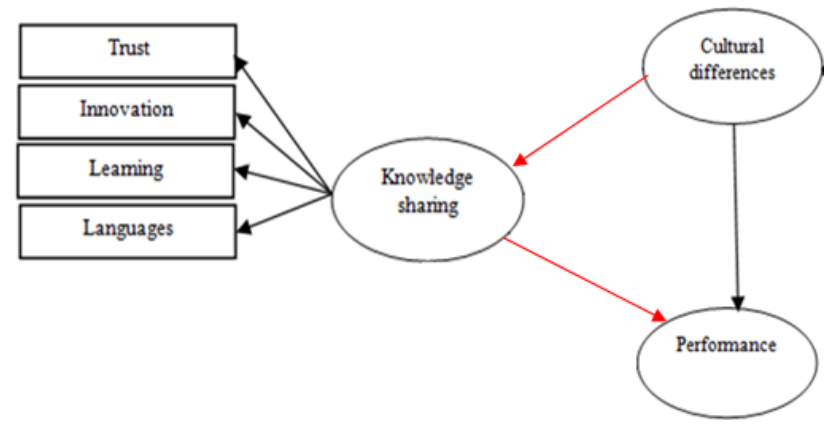

Figure (1) Impact of the cultural differences on the knowledge sharing

\section{DATA COLLECTION}

The method of data collection which is fitting for this study is a quantitative approach using questionnaires. The questionnaire is a printed list of questions was distributed to the employees of (multicultural Construction company in Malaysia) where there are multicultural employees; the respondents were asking to answer basic on their experience in the Construction projects in order to come out with the answers about the influence of the cultural differences on the knowledge sharing in the construction Project.

\section{ANALYSIS METHOD}

System dynamic simulation software is used in this study seeking to assess the level of the transferred knowledge in the construction project among the terms members of the project and also assessing the effect of the cultural diversity on the flowing the knowledge in the construction project and how that leads to impact the project performance under the impact of the cultural difference. The gathered data or information is analysis by establishing suitable formula in the system dynamic suite the study type in order to come out with meaningful statistics result, the simulated data is summarized in the tables and graphs.

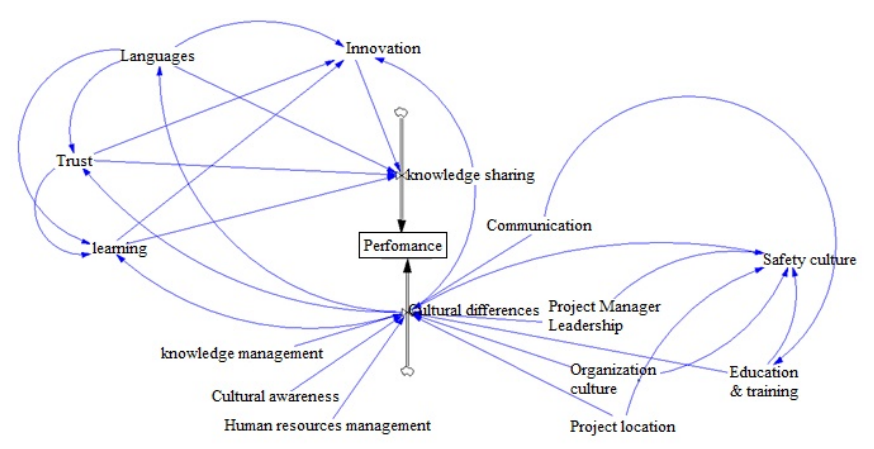

Figure (2) concept of the system dynamic simulation

\section{THE RESULT AND DISCUSSION}

The table (1) is displaying general information about the respondents, from the collected questionnaire is found all the respondents full in three level of the education which are they, high diploma and bachelor's degree and master degree as shown in the table. Also the positions of the respondents in company are shown which are senior executive, assistant manager, Project manager, Assistant general manager, General manger and Deputy Project manager. The ages of the respondents are obtained as well as shown in the table which the entire ages of respondents are realized to full in between 27 up to 50 years old, whilst the experience of the respondents in the multicultural construction organization start from 4 up to 24 year.

Table (1) general information about the respondents

\begin{tabular}{|c|c|c|c|c|c|}
\hline \multicolumn{2}{|c|}{ Education level } \\
\hline \multicolumn{2}{|c|}{ Diploma } & \multicolumn{2}{c|}{$\begin{array}{c}\text { Bachelor's } \\
\text { Degree }\end{array}$} & \multicolumn{2}{c|}{ Master degree } \\
\hline \multicolumn{2}{|c|}{ Position } & \multicolumn{2}{c|}{ The ages } & \multicolumn{2}{c|}{ Experiences } \\
\hline $\begin{array}{c}\text { Senior } \\
\text { executive }\end{array}$ & 1 & 27 & 2 & 4 & 2 \\
\hline $\begin{array}{c}\text { Project } \\
\text { manger }\end{array}$ & 2 & 44 & 1 & 18 & 1 \\
\hline $\begin{array}{c}\text { Assistant } \\
\text { manager }\end{array}$ & 3 & 29 & 1 & 24 & 1 \\
\hline $\begin{array}{c}\text { General } \\
\text { manger }\end{array}$ & 1 & 50 & 1 & 12 & 1 \\
\hline $\begin{array}{c}\text { Assistant } \\
\text { general } \\
\text { manager }\end{array}$ & 1 & 33 & 1 & 5 & 1 \\
\hline $\begin{array}{c}\text { Deputy } \\
\text { project } \\
\text { manager }\end{array}$ & 1 & 31 & 1 & 7 & 1 \\
\hline Unknown & 1 & 46 & 1 & 8 & 1 \\
\hline & & 32 & 1 & 10 & 1 \\
\hline & 39 & 1 & unknown & 1 \\
\hline
\end{tabular}

The graph (1) is representing the effectively of flowing the knowledge between the team members and how it reflect on the project performance without effect of cultural diversity, and how the cultural diversity influence the flowing knowledge in the construction organization and leads to influencing the outcome of project performance. 


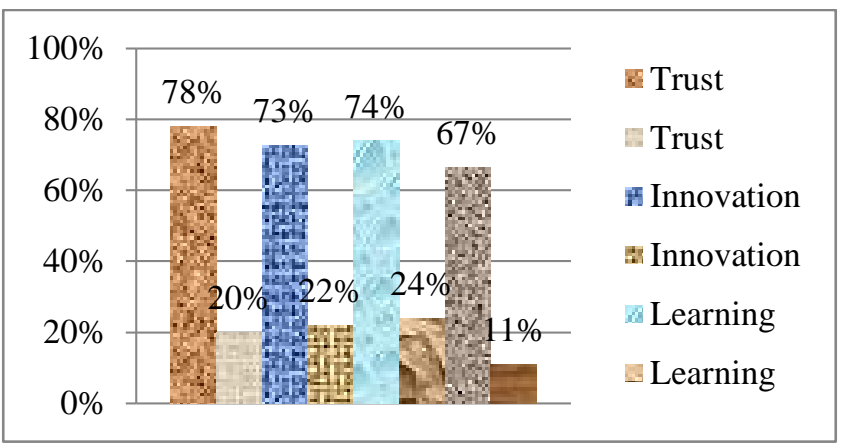

Graph (1) effect of the cultural diversity on the knowledge sharing

As its shown in the graph (1) the knowledge flowing between the workers in the construction project without the impact of the cultural differences is high which that exemplify in $78 \%$ trust in the bar number (1), $73 \%$ innovation in bar number (3), $74 \%$ learning in the bar number (5) and $67 \%$ for the languages in the bar number (7).

The graph (1) also is shown the cultural differences impact the knowledge flowing in the construction site, and how the productivity is influenced in the project performance.

In the bar number (1) the cultural difference influence on the knowledge sharing reduced the degree of trust to $20 \%$ from $78 \%$ in construction site. As in bar number (4) the influence of the cultural diversity on the flowing the knowledge lowers the innovation in the construction project to $22 \%$ from $73 \%$. Whilst in bar number (6) the cultural diversity influence the flowing of the knowledge in the construction project lower the level of the learning to $24 \%$ from $74 \%$. Even as in bar number (8) the cultural differences impact on the knowledge sharing reduced the level of the communication or the languages to $11 \%$ from $67 \%$ in the construction projects.

Graph (2) is demonstrating the cultural differences impact on the knowledge sharing which that reflecting on the project performance in the construction site.

a. the blue line in the graph representing the knowledge sharing in the construction project without the cultural influences

b. The red line is representing the cultural differences impact on the knowledge sharing in the construction project.

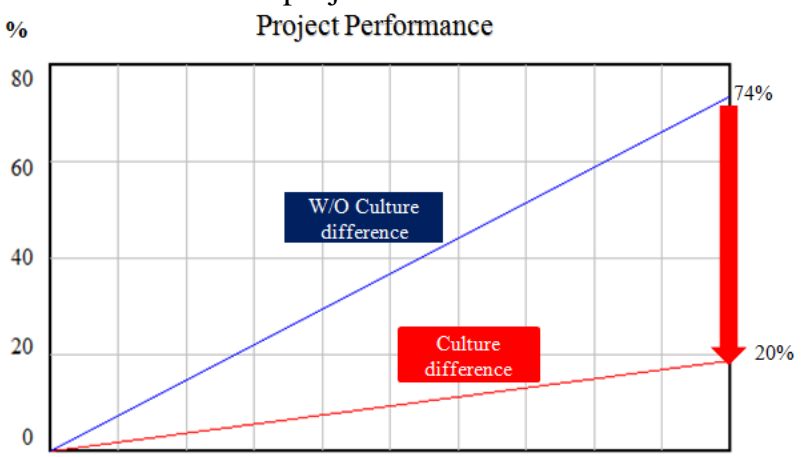

Graph (2) the performance in the construction project

From the result of graph (2) it is declared that the performance of the project is high as $74 \%$ in the construction project without the cultural differences impact, which that because more knowledge is shared among the workers in the construction project

In graph (2) the performance of the project is sharply decreased to $20 \%$ in the construction project due to the cultural differences influences on the knowledge flow can be interpreted as less exchanging the knowledge between the individuals in the construction projects.

\section{CONCLUSION}

The researcher intends to conclude the outcome of the survey that conducted to identify the impacts of cultural differences on knowledge sharing in the construction project and it influences the performance of the project (safety, quality, and cost).

The construction industry itself is facing numerous predicaments due to the cultural diversity influences on the flowing the knowledge in the construction site. These problems accumulated due to the complexity of the nature of the construction sector that happened due to impact of cultural difference.

The cultural differences impact on the knowledge sharing in the construction projects can be translated from the respondents' answers in graph (1). The respondents denoted that the cultural diversities have negative effect on the flowing the knowledge in the construction projects, which that leads to lack of sharing the knowledge in the project between the workers. In the graph (1) stated the cultural difference impact on the knowledge flowing lower the capacity of the learn, reduce the level of the trust in the construction project, and decrease the smoothing of communication between the worker and that bring down the innovation to occur in the construction sector. it proven in bar number (1) and bar number (2) in graph (1) the trust is reduced from $73 \%$ to $20 \%$ due to influence of the cultural differences in the construction industry.

Large number of respondents agreed that the impact of cultural differences on the knowledge sharing is one of the issues that influence the project performance negatively in the construction project as cleared out in graph (2) the project performance is high as $74 \%$ due to flowing the knowledge among the workers in the construction projects, while the project performance is sharply reduced to $18 \%$ due to the cultural diversity influence the flowing of knowledge in the construction sector which that strongly affect the outcome of the projects.

\section{REFERENCES}

[1] Ankrah, N. A. \& Proverbs, D. Treading the softer areas of construction management: A critical review of culture, IN KHOSROWSHAHI, F. (ed.), Proceedings of the 20th Annual ARCOM Conference, Edinburgh, 1, 551-558. (2004)

[2] J.-N. The impact of knowledge sharing, organizational capability and partnership quality on IS outsourcing success. Information and Management, 38, 323-335. (2001)

[3] Dixon, N. Common knowledge: how companies thrive by sharing what they know, Boston: Harvard Business School Press. (2000)

[4] Xiong, S. and Deng, H. Critical success factors for effective knowledge sharing in Chinese Joint Ventures', in 19th Australasian Conference on Information Systems 
Knowledge Sharing in Chinese, Christchurch, 3-5 Dec (2008).

[5] Ipe, M. Knowledge Sharing in Organizations: A Conceptual Framework. Human Resource Development Review, 2 (4), pp.337-359. (2003)

[6] Cabrera, A. and Cabrera, E. Knowledge Sharing Dilemmas. Organizational Studies, 23 (5), pp.687-710. (2002)

[7] Parekh, R. A. Knowledge sharing: collaboration between universities and industrial organizations, in International Conference on Academic Libraries (ICAL2009), Delhi, INDIA, 5th to 8th October, Delhi University library System, University of Delhi (North Campus), 146151. (2009).

[8] Hendriks, P. Why share knowledge? The influence of ICT on the motivation for knowledge sharing. Knowledge \& Process Management, 6(2), 91-100. (1999).

[9] Goodman, P. D. \& Darr, E. D. Computer-aided systems and communities: mechanisms for organizational learning in distributed environments. MIS Quarterly, 22(4), 417-440 (1998).

[10] Teruya, S. A. An analysis of the value of implementing knowledge management. Unpublished doctoral dissertation, Pepperdine University, California, United States (2003).

[11] Weiss, L. Collection and connection: The anatomy of knowledge sharing in professional service firms. Organization Development Journal, 17(4), 61-77(1999).

[12] Finestone, N., and Snyman, R. Corporate South Africa: making multicultural knowledge sharingwork'. Journal of Knowledge Management, Vol. 9, No. 3, pp 128-41 (2005).

[13] Hofstede, G. Culture's consequences: comparing values, behaviors, institutions, and organizations across nations, London; Thousand Oaks, California, Sage Publications (2001).

[14] Thiessen, M.S.W., Hendriks, P.H.J., and Essers, C. Research and development knowledge transfer across national cultures", In Pauleen, D.J. (ed.), Cross-Cultural Perspectives on Knowledge Management, Libraries Unlimited, Westport, USA, pp 219-243 (2007).

[15] Husted, K. and Michaiova, S. Knowledge Sharing in Russian Companies with Western Participation. Management International, 6(2), pp.17-28 (2002).

[16] Argote, L., McEvily, B., \& Reagans, R. Managing knowledge in organizations:An integrative framework and review of emerging themes. Management Science , 49 (4) 571-582 (2003).

[17]Bodley, J. H. An Anthropological Perspective, Cultural Anthropology: Tribes, States, and the Global System (1994).

[18] Ankrah, N. A. \& Proverbs, D. Treading the softer areas of construction management: A critical review of culture, IN KHOSROWSHAHI, F. (ed.), Proceedings of the 20th
Annual ARCOM Conference, Edinburgh, 1, 551-558 (2004).

[19] Thiagarajan, T., Zairi, M., Dale, B. A proposed model of TQM implementation based on an empirical study of Malaysian industry, International Journal of Quality \& Reliability Management. Vo1. 18 No 3. Pp. 289-306 (2001).

[20] Glendon, A.I. and McKenna, E.F. Human Safety and Risk Management. London: Chapman and Hall (1995).

[21]Randeree, E. Knowledge management: Securing the future. Journal of Knowledge Management, (10)4, 145-156. doi: 10.1108/13673270610679435(2006).

[22] Liebowitz, J. A knowledge management strategy for the Jason Organization: A case study. The Journal of Computer Information Systems, 44(2), 1-5 (2004).

[23] Marshall, N., \& Brady, T. Knowledge management and the politics of knowledge: Illustrations from complex products and systems. European Journal of Information Systems, 10(2), 99-112 (2001).

[24] Lastres, S. A. Aligning through knowledge management. Information Outlook, 15(4), 23-25 (2011).

[25] O’Dell, C., and C.J. Grayson. If only we knew what we know: identification and transfer of internal best practices. California Management Review 40(3): 154-174 (1998).

[26] Reid, F. Creating a knowledge sharing culture among diverse business units. Employment Relations Today , 30 (3), 43-49 (2003).

[27] Mesmer-Magnus, J. R., \& DeChurch, L. A. Information sharing and team performance: A meta-analysis. Journal of Applied Psychology , 94 535-546 (2009).

[28] Lin, H. -F. Knowledge sharing and firm innovation capability: An empirical study. International Journal of Manpower, 28(3/4) 315-332 (2007d).

[29] Hansen, M. T. Knowledge Networks: Explaining Effective Knowledge Sharing in Multiunit Companies. Organization Science, 13 (3), 232-248 (2002).

[30] Arthur, J. B., \& Huntley, C. L. Ramping up the Organisational Curve: Assessing the Impact of Deliberate Learning on Organisational Performance under Gainsharing. Academy of Management Journal , 48 (6), 1159-1170 (2005).

[31] Collins, C. J., \& Smith, K. G. Knowledge exchange and combination: The role of human resource practices in the performance of high-technology firms. Academy of Management Journal, 49(3) 544-560 (2006).

[32] Cummings, J. N. Work groups, structural diversity, and knowledge sharing in a global organisation. Management Science, 50(3), 352-364 (2004).

[33] Kang, Y.-J., Kim, S.-E., \& Chang, G.-W. The Impact of Knowledge Sharing on Work Performance: An Empirical Analysis of Public Employees' Perceptions in South Korea. 